\title{
Las dinámicas fronterizas en el siglo XX-XXI: un espejo de la evolución del orden mundial
}

\author{
Carlos A. Coca Gamito \\ Y GEORGIOS BALTOS*
}

\section{RESUMEN}

El artículo analiza las dinámicas fronterizas desde el comienzo del siglo $X X$ a través de una revisión bibliográfica apoyada en el análisis de datos cuantitativos y dos casos de estudio.

La tesis central es que existe un conflicto entre las fronteras culturales y las político-territoriales, desafiando los límites geográficos reconocidos oficialmente. La frontera político-territorial es un fenómeno jurídico, una demarcación lineal que establece los límites espaciales dentro de los cuales el estado nación ejerce la soberanía de forma exclusiva, eficaz, autónoma respecto al exterior y bajo el reconocimiento de la legislación internacional. La frontera cultural es un fenómeno histórico que responde a hechos vitales y no a una construcción jurídica ni política ni intelectual. Podemos definirla como un área sociocultural habitada por una población que comparte una serie de elementos simbólicos, costumbres y valores. La gestión del conflicto entre los dos tipos de frontera depende de los desarrollos históricos que tienen lugar en el ámbito de las relaciones internacionales

Nuestra tesis muestra que dichas dinámicas pueden articularse en torno a tres ejes. El primero está guiado por el auge del proceso globalizador y la consecuente apertura de fronteras. La apertura de fronteras puede definirse como el aumento en la porosidad de los símbolos, costumbres y valores compartidos en un área sociocultural respecto a los del exterior y/o la disminución de barreras al tránsito físico. Se le contrapone otro eje que lleva al cierre de fronteras, espoleado por los procesos de descolonización, la disolución de la URSS y el resurgir del nacionalismo. El cierre de fronteras se define como la disminución de la porosidad fronteriza o el aumento de las barreras al tránsito físico. El tercer eje está marcado por las disputas territoriales, fundadas sobre diferencias culturales, que llevan a intentar modificar las fronteras oficiales. La modificación de fronteras se da bien cuando un estado nación busca alargar la línea fronteriza que delimita el área bajo su soberanía o un grupo sociocultural trata de delimitar un territorio soberano frente al exterior, bien cuando un área sociocultural definida se expande o retrae sea por el auge o decline de su cultura sea por el del grupo humano que la representa.

Los acontecimientos históricos para el análisis de los tres ejes citados provienen de fuentes bibliográficas, periodísticas y de bases de datos.Además, mostramos como la teoría se plasma en dos casos de estudio actuales, el independentismo catalán y el intento venezolano de crear un nuevo poder regional en el Caribe.

\section{Palabras clave}

Relaciones Internacionales; Dinámicas Fronterizas; Fronteras Político-Territoriales; Fronteras Culturales; Historia Económica.

\section{TitLE}

Border dynamics in the 20-2Ist century: a mirror of the world order evolution

\section{Abstract}

The article analyses border dynamics since the beginning of the 20th century through a literature review supported with the analysis of quantitative data and two case studies.

DOI:

http://doi.org// 0.15366/relacionesinternacionales2020.44.004

Formato de citación recomendado:

COCA GAMITO, Carlos A. y BALTOS, Georgios (2020), “Las dinámicas fronterizas en el siglo XX-XXI: un espejo de la evolución del orden mundial”, Relaciones Internacionales, $n^{\circ} 44$, pp. 63-86.

* Carlos A. COCA GAMITO, Licenciado en Historia (Universidad de Sevilla). Graduado en Economía (UNED). Máster en Integración Económica (Colegio de Europa). Ciudadano Honorífico de Brujas.Auditor Interno en el Instituto Universitario Europeo. Publicaciones en College of Europe $y$ Bulletin of Geography. Socioeconomic Series. Actualmente cursando un doctorado en Economía Aplicada en la Universidad de Salamanca.

\section{Georgios}

BALTOS,

Colaborador del Instituto Universitario Europeo. Doctor por la Universidad del Egeo. MBA CIA, CRMA, CCSA, Auditor y Asesor Legal. Experto en geopolítica. Ha servido para la OTAN en el Joint Force Command Lisbon, estudiado asesoría legal y gestión de recursos en el Oberammergau NATO School y participado en misiones en Etiopia prestando apoyo a la Unión Africana.

Recibido:

17/09/2019

Aceptado: 19/03/2020 
The central thesis is that there is a contradiction between the cultural and the geopolitical borders, challenging the official territorial limits. The geopolitical border is a legal phenomenon, a lineal boundary that establishes the territorial limits within which the nation-state exercises its sovereignty in an exclusive and effective manner, autonomous with respect to any foreign authority and under the recognition of the international law. The cultural frontier is a historical phenomenon shaped by emotional developments and not a legal, political or philosophical construction. It can be defined as a sociocultural area occupied by a population that shares a series of symbolic elements, customs and values. The management of the conflict between both types of borders depends on the historical developments that have taken place within the international relations' field.

In order to analyse how geo-political borders and cultural frontiers interact between them we apply a hypothetic-deductive method. Firstly, we establish a theoretical framework that defines five basic analytical concepts shaping border dynamics. Those concepts are cultural frontier, geo-political border, closure axis, opening axis and modification axis. We design a model that explains how such concepts interact between them and we gather and analyse the evolution of a series of quantitative variables that allow us to empirically introduce their relationship along time. The construction of the theoretical framework, as well as the selection and interpretation of quantitative variables, comes together with the introduction of quotations and bibliography that back it up. Moreover, we apply the conclusions deducted from the global analysis to two case studies. The similarities and differences between both case studies are pointed out and we summarize the dynamics shaping the current management of borders. Finally, we offer some recommendations in order to design an effective and efficient geostrategy.

The management of borders is articulated around three axes: closure, opening and modification. In other words, nationstates aim to achieve their geostrategic objectives through the modification, closure or opening of their cultural frontiers or/and geopolitical borders. The opening of borders/frontiers can be defined as the increase in the porosity to the outside world of the symbols, customs and values that are shared within a sociocultural area; and/or the wave of barriers to physical transactions - people, goods, capital flows, etc.-. On the other hand, the closure of borders/frontiers happens when the aforementioned porosity decreases or the barriers are strengthened. Finally, the modification of borders/frontiers can be either expansive or contractive as well as happening in the geopolitical dimension or the cultural one. Regarding the geopolitical dimension, the nation-state aims to expand the lineal boundary that mark out the area under its sovereignty or the sociocultural group aims to delimit to the outside world a territory under its exclusive sovereignty. Concerning the cultural dimension, a specific sociocultural area enlarges or retracts either as a consequence of the rise or decline of its culture or of the human group that embraces it. The evolution of the three axes is proxied by a series of variables and their trends. Moreover, the historical events laying down the foundations of the analysis of the three axes are gathered from different sources: bibliography, newspapers and data bases. Moreover, we show how the theory is captured in two current case studies, the independentism in Catalonia and theVenezuelan attempt to create a new regional power in the Caribbean.

While the globalization process fosters the opening of borders, the will of the nation-state to safeguard its historical rights and the international status quo drives its closure. On the other hand, the modification of borders is marked by territorial disputes arising from the contradictions between geopolitical borders and cultural frontiers, often exacerbated by the dynamics related to the two previous axes. The territorial dispute between Venezuela and the Cooperative Republic of Guayana is an example of such a dynamic. On the one hand, the State of Venezuela tries to safeguard its traditional rights presenting the dispute as a national question.At the same time, globalization lengthens cultural boundaries while Venezuela revives the ideological division between a capitalist and a socialist world. The closure of borders and frontiers, marked by the nationalist revival, and the opening, driven by the globalization process, act as a catalyser of borders modification.

The article is structured by an introduction and six sections. The introduction defines the concepts of geopolitical border and cultural frontier. Moreover, it establishes the theoretical framework used to analyse the evolution of both types of borders and how the interaction between them shapes international relationships during the 20th and 21 st centuries. The first section introduces the three axes —closure, opening and modification - along which the management of borders develops during the period under analyses and the relationships arising between them. The second section analyses the closure axis that is driven by the rise of nationalism, the Cold War and the decolonisation process. We use a series of variables to proxy how such an axis evolved along time: total number of international organizations, creation and end of international organizations, net foreign direct investment flows, international trade of goods, attitude of the government towards immigration and number of United Nations peacekeeping missions. The third section does the same for the opening axis. The opening of borders is fostered by the expansion of economic and political liberalism through the globalization process. We use the same variables as in section two to empirically assess the evolution of the opening axis. Section number four introduces the modification axis and how the changes of borders and frontiers are related to events linked to the opening and closure axes. The section analyses three types of modifications (territorial concessions, declarations of independence and annexations). Data about modifications are gathered from The Correlates of War Project and The World Factbook data bases. Section number five shows how the tension between cultural and geopolitical borders determines the management of borders nowadays, following the three axes of closure, opening and modification outlined above. Firstly, we introduce the case study of Catalonia, which is mainly related to the closure axis. Secondly, we analyse the case study of Guayana Esebequio and the territorial dispute between Venezuela and the Cooperative Republic of Guayana. Finally, we compare the differences and similarities between both case studies. The last section consists of the conclusions and political recommendations that we extract from our research so that policy makers can implement efficient and effective policies on borders managements.

\section{KEYWORDS}

International Relations; Border Dynamics; Geopolitical Borders; Cultural Frontiers; Economic History. 
I

\section{ntroducción}

Abundantes debates contemporáneos han resaltado el uso y abuso del concepto de frontera como instrumento de análisis de la geopolítica' actual. La aplicación del concepto de frontera al análisis de fenómenos geopolíticos presupone una realidad no siempre evidente, el carácter multidimensional de estas. Aunque las fronteras se hallan utilizado secularmente para delimitar el espacio donde un estado nación ejerce el monopolio del poder político — dimensión políticoterritorial- también trazan los confines entre etnias y poblaciones que difieren en sus cosmovisiones y modos de organizarse como sociedad — dimensión cultural—.

La frontera políticoterritorial es un fenómeno jurídico que podemos asociar con el concepto de boundary (Kristof, 1959, pp. 269-282) es decir, una demarcación lineal que establece los límites espaciales dentro de los cuales el estado nación ejerce la soberanía de forma exclusiva, eficaz, autónoma respecto al exterior y bajo el reconocimiento de la legislación internacional. La frontera cultural es un fenómeno histórico que se relaciona con el concepto de frontier (Kristof, 1959, pp. 269-282), aunque sin agotarlo, respondiendo a hechos vitales y no a una construcción jurídica, ni política, ni intelectual. Podemos definirla como un área sociocultural (Medina García, 2019, pp. 73-95) habitada por una población que comparte una serie de elementos simbólicos, costumbres y valores (Grimson, 2019). Así, dado que los símbolos se expanden y contraen a lo largo del espacio geográfico, la frontera cultural no es fija sino dinámica y cambiante (Grimson, 2019, pp. 14-17).

Las fronteras políticas están cada vez menos en el origen de los conflictos internacionales. Aunque aún hay zonas sobre las cuales varios estados disputan sus límites territoriales, caso de Venezuela y Guayana, la principal fuente de inestabilidad del orden internacional se deriva de la no adscripción de las fronteras culturales a esos límites.Así, el conflicto entre frontera cultural versus frontera política es el punto de partida de la cuestión catalana.

Para analizar como los dos tipos de fronteras interactúan entre si seguimos un método hipotético deductivo. Establecemos un marco teórico definiendo las cinco categorías básicas de nuestro análisis en la introducción y la sección primera. Dichos conceptos son frontera cultural, frontera políticoterritorial, eje de cierre, eje de apertura y eje de modificación. Especificamos cómo estos cinco fenómenos teóricos interactúan entre sí y, en las secciones segunda a cuarta, seleccionamos y analizamos la evolución de una serie de variables cuantitativas que permiten modelar su interacción en el tiempo. La construcción del marco teórico, así como la selección e interpretación de variables, viene acompañado por la introducción de citas y referencias bibliográficas que las respaldan. Posteriormente, aplicamos las conclusiones extraídas del análisis global de los fenómenos presentados a dos casos de estudio, comparamos sus similitudes y semejanzas y concluimos indicando cuáles son las dinámicas que subyacen en la gestión de fronteras actual. Finalmente se extraen algunas recomendaciones sobre cómo diseñar una geoestrategia eficiente y efectiva.

El artículo se estructura en seis secciones. La primera sección introduce el marco teórico y los conceptos claves utilizados para analizar la evolución de la gestión de fronteras a lo largo del siglo XX y principios del XXI. Desde las secciones segunda a la cuarta, se analizan a escala global

\footnotetext{
Disciplina que estudia cómo la geografía física y humana, influencian la política y las relaciones internacionales.
} 
y mediante el estudio de variables cuantitativas, la evolución de los tres ejes en torno a los cuales se articulan esa gestión. La sección quinta aplica las tendencias globales y los conceptos teóricos previamente definidos a los casos de estudio de Cataluña y Venezuela. Por último, la sección sexta presenta las conclusiones.

\section{Marco teórico. La rotación de la gestión de fronteras en torno a tres ejes geoestratégicos}

El choque de civilizaciones (Huntington, 1997) requiere la invención de límites políticoterritoriales ficticios entre culturas, cuyas fronteras no corresponden con aquellas de los estados nación. Dicha incoherencia entre las fronteras culturales y las políticas, a menudo, supone un desafío a los límites territoriales reconocidos oficialmente. El origen del conflicto puede estar tanto en que los límites fronterizos son demasiado extensos, obligando a diferentes grupos étnicos a compartir el mismo espacio geopolítico como en el caso español, o demasiado estrechos, de modo que un ethnos ${ }^{2}$ se ve dividido entre distintos estados nación. Por otra parte, el auge del nacionalismo y el restablecimiento del proteccionismo económico en Occidente hacen que para el estado nación sea fundamental definir y reforzar sus fronteras políticoterritoriales, dado que le permiten mantener su papel vertebrador de las relaciones internacionales y la política nacional.

El curso seguido por las relaciones internacionales muestra el dinamismo de los ejes que articulan la gestión de las fronteras $y$, por tanto, la geoestrategia mundial y regional. Por geoestrategia nos referimos a la planificación racional de las actuaciones estatales sobre el territorio geográfico en aras de alcanzar sus objetivos del modo más eficiente y seguro. La gestión de las fronteras es un instrumento básico de la geoestrategia.

Reformulando a Gerard Delanty (2006), Chris Rumford (2006) y Bastian Sendhardt (20I3) podemos decir que los tres ejes que articulan la gestión de fronteras son la modificación, el cierre y la apertura. En otras palabras, los estados nación tratan de alcanzar sus objetivos geoestratégicos modificando, cerrando o abriendo sus fronteras culturales y/o políticoterritoriales. La apertura de fronteras puede definirse como el aumento en la porosidad de los símbolos, costumbres y valores compartidos en un área sociocultural respecto a los del exterior y/o la disminución de barreras al tránsito físico — personas, mercancías, flujos de capital, etc.- . Por el contrario, el cierre de fronteras se define como la disminución de esa porosidad o el aumento de esas barreras. Por su parte, la modificación de fronteras puede ser tanto expansiva como contractiva y darse en la dimensión políticoterritorial o cultural. En la primera dimensión, un estado nación busca alargar la línea fronteriza que delimita el área bajo su soberanía o un grupo sociocultural trata de delimitar un territorio soberano frente al exterior. En la segunda dimensión, un área sociocultural (Medina García, 2019, pp. 73-95) definida se expande o retrae sea por el auge o decline de su cultura sea por el del grupo humano que la representa.

Mientras que el proceso globalizador favorece la apertura de fronteras, la voluntad del estado nación de salvaguardar sus derechos históricos y el status quo internacional favorece su cierre. Finalmente, la modificación de fronteras viene marcada por las reclamaciones territoriales que explotan las contradicciones entre fronteras políticas y culturales, muchas veces exacerbadas 2 Entendemos ethnos en su sentido colectivo, como comunidad que comparte unos rasgos y modos de
comportamiento que le otorgan una identidad cultural particular (RAE, 2020). 
por las dinámicas relacionadas con los dos ejes anteriores. Podemos ver como esto se plasma en las reclamaciones territoriales de Venezuela hacia la República Cooperativa de Guayana —en adelante Guayana-. Por una parte, el Estado venezolano trata de salvaguardar sus derechos tradicionales convirtiendo la disputa territorial en una cuestión nacional. A la vez, la globalización alarga las fronteras cultuales mientras que Venezuela reaviva la división ideológica entre un mundo capitalista y otro socialista (Kristof, 1959, pp. 269-282). El cierre de fronteras, marcado por el resurgir nacionalista, y la apertura, dictada por la globalización, actúan como catalizador de las modificaciones fronterizas.

El caso del independentismo catalán, sin llegar a suponer una modificación fronteriza, también muestra como los tres ejes interactúan entre sí. Por una parte, el proceso de integración europeo supuso una apertura de fronteras no solo en España sino también en Cataluña. Esto aumentó la porosidad de la cultura catalana respecto a la europea y, relativamente, disminuyó su dependencia de los modelos españoles. En el terreno económico la integración europea hace que Cataluña sea menos dependiente de los mercados españoles de bienes, servicios, capitales y mano de obra. A la vez, el resurgimiento del nacionalismo, no solo en Cataluña sino en toda Europa, se plasmó en una progresiva diferenciación de sus símbolos culturales propios respecto a los del resto de España, llevando a un proceso de cierre de fronteras culturales. Este cierre no habría sido tan fácil, tal vez ni siquiera posible, sin la previa apertura hacia Europa.Así, el intento por una parte de la sociedad catalana de modificar sus fronteras políticoterritoriales nace de unos procesos de apertura y cierre de fronteras, los cuales agravaron el conflicto entre la frontera cultural catalana y la políticoterritorial española.

\section{Ejes geoestratégicos de la gestión de fronteras}

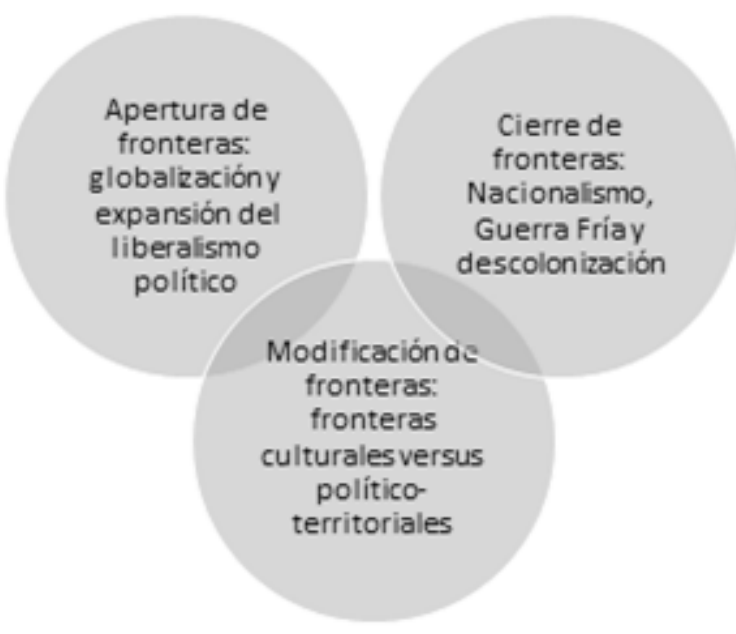

Fuente: Creación propia

\section{Primer eje: cierre de fronteras. Nacionalismo, Guerra Fría y descolonización}

La primera mitad del siglo XX está marcada por la evolución de las relaciones internacionales a lo largo del eje de cierre. La variable histórica que promueve este cierre es el auge del nacionalismo agresivo. Las dos guerras que sacuden al mundo en la primera mitad del siglo, y que fueron 
consecuencia del nacionalismo, frenaran el proceso de construcción de un sistema de gobernanza global y los procesos de integración económica.

El gráfico 2 (Pevehouse et al., 2019) muestra el número de organizaciones internacionales - Ol- en activo que hay en el mundo, por décadas, entre 1900 y 2014 . El número de Ol en activo aumenta de forma lineal durante la segunda mitad del siglo, mientras que en la primera lo hace a saltos, determinado por el intento de solucionar los problemas originados por el nacionalismo. Así, en la década de los veinte hay un salto en busca de construir un sistema de gobernanza global que evite la repetición de desastres como el de la Primera Guerra Mundial. Entre 1930-1939 y 1939-1945 el número de Ol en activo pasa solo de veintisiete a treinta y tres. Sin embargo, en 1945- 1950 pasamos a tener cuarenta y nueve OI en activo. La comunidad internacional respondió así a los nacionalismos agresivos que desencadenaron la guerra y apostó por un sistema de gobernanza global que abriese las fronteras en busca de evitar sus futuras modificaciones.

\section{Organizaciones Internacionales. Mundo, 1900-20I4}

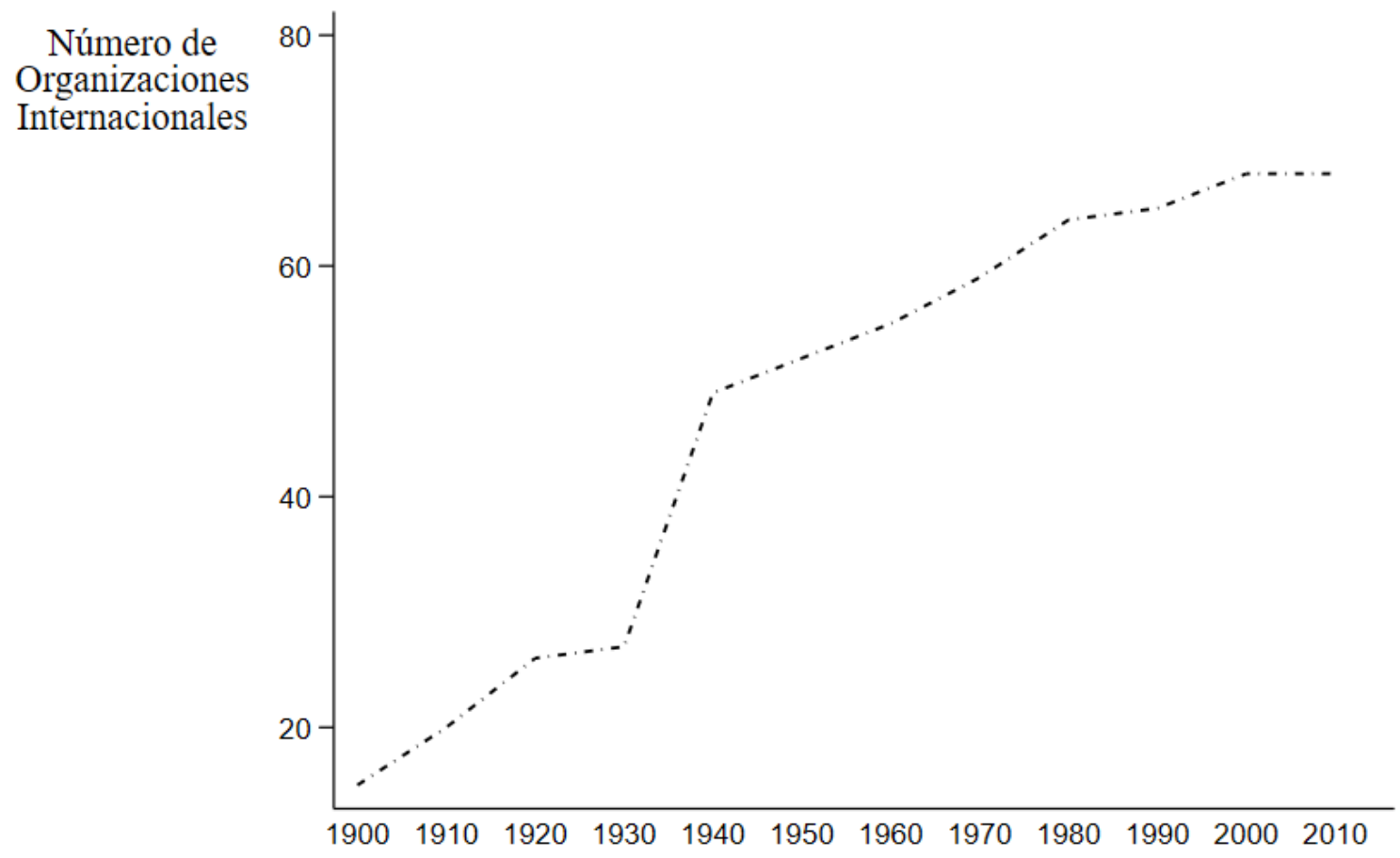

Fuente: Pevehouse et al. (2019)

La época que sigue a la Segunda Guerra Mundial presenta una cierta dualidad respecto a la gestión de fronteras. Si bien la globalización avanza abriendo fronteras, lo hace de forma dual y dentro de los dos bloques conformados por la Guerra Fría. La gran frontera cultural que origina el choque entre capitalismo y bolchevismo hace que se dé una integración mundial dual y separada, aunque hubo momentos de distensión y lugares de encuentro (Kristof, 1959, pp. 269-282). En este sentido, la formación de un tercer bloque por el grupo de países no alineados facilitó, aunque no siempre pacíficamente, la creación de un área sociocultural más permeable que ofrecía un espacio 
de encuentro entre los dos grandes bloques.

Pero la descolonización actuó sobre todo como un vector del eje de cierre, aumentando las barreras físicas entre antiguas colonias y metrópolis, sin que en un primer momento la integración regional de África, Asia o Oceanía supusiese una alternativa al antiguo método de integración de estas economías en el sistema mundo. Además, la revitalización de las costumbres culturales, lenguas y universo simbólico de las comunidades tradicionales ayudó a levantar la frontera cultural respecto a la metrópoli.Todo esto se materializó mediante actuaciones en el eje de modificación de fronteras como veremos más adelante.

Antony Gerald Hopkins (2017) plantea, sin embargo, una lectura alternativa. Según Hopkins a partir de los años cincuenta se entra en la fase postcolonial del proceso globalizador que perdura hasta nuestros días. Nuevas circunstancias dejaban sin sentido al mecanismo de integración global impulsado bajo el auge de los estados nación. La financiarización de la economía mundial, las exigencias de equilibrio político de la Guerra Fría y las demandas de autodeterminación forzaron que los imperios extraterritoriales diesen paso a modos de neocolonialismo de mercado ligados a la difusión de las doctrinas del soft power. Una vez que los intereses de occidente quedaban salvaguardados bajo un nuevo sistema de neocolonialismo global y el final de la Guerra Fría era evidente, todo parecía apuntar a un futuro de paz y progreso estable. Sin embargo, los hechos acabaron demostrando que Francis Fukuyama (1992) se precipitó al anunciar el final de la historia señalado por el triunfo de los sistemas democráticos y el libre mercado.

De hecho, a la luna de miel entre el liberalismo político y el libre mercado, que se da en los años noventa a escala mundial, le siguió un retroceso en cuanto a la apertura de fronteras.A partir de los noventa el número de $\mathrm{Ol}$ en activo se estabiliza mientras que, como podemos ver en el gráfico 3 (Pevehouse et al., 2019), el número de Ol cesadas aumenta y el de creadas se reduce. La crisis financiera de 2007-2008 confirma el cambio de ciclo a favor del eje de cierre con la reducción de los flujos netos de inversión extranjera directa y el estancamiento del comercio internacional de mercancías, como muestran los gráficos 5 y 6 reproducidos en la siguiente sección. 


\section{Organizaciones Internacionales. Mundo, I 900-20 I4}

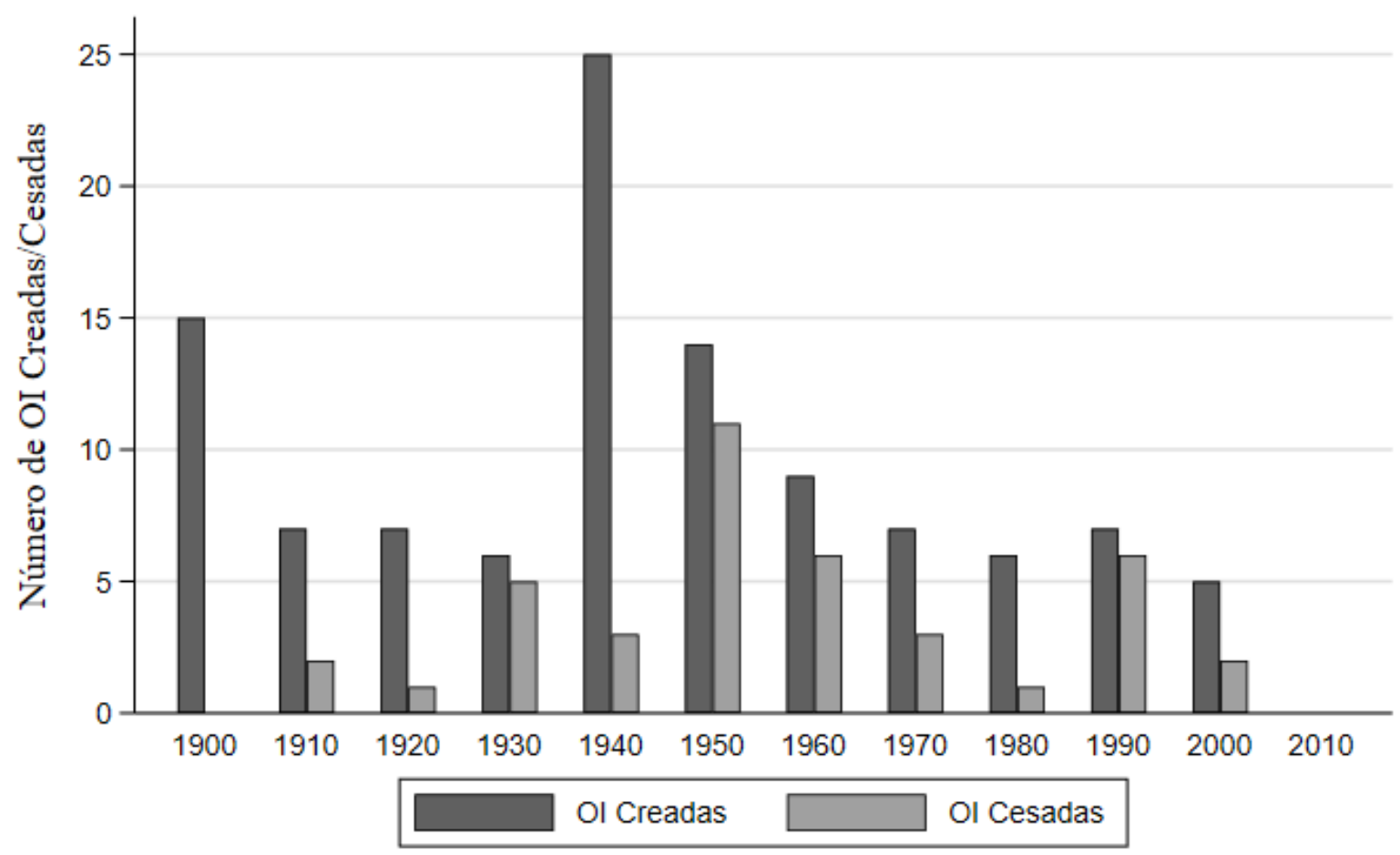

Fuente: Pevehouse et al. (2019)

El repunte nacionalista que siguió a la crisis financiera no solo significó un aumento del proteccionismo económico, sino que también tuvo una vertiente política que se refleja en el auge de partidos y líderes políticos que defienden la xenofobia, el identitarismo y el supremacismo. Esto puede verse en diversos acontecimientos históricos recientes como, por ejemplo, el rebrote del discurso identitario e independentista en Cataluña o la intensificación del conflicto entre Venezuela y Guayana por el territorio de Esebequio.

A nivel más agregado las actitudes frente a la inmigración constituyen una buena proxy para medir la fuerza del eje de cierre de fronteras. El gráfico 4 muestra la percepción de la inmigración que tienen los diferentes gobiernos en el mundo y por continente ${ }^{3}$. Los gobiernos han pasado de considerar, como media global en 2005, que la cantidad de inmigrantes era óptima o inferior a la deseada a creer que es excesiva, aunque parece que la tendencia comienza a revertir. No olvidemos, de todas formas, que el gráfico muestra la actitud gubernamental y esta no siempre refleja adecuadamente el sentir social. Incluso aunque los partidos que defienden la xenofobia y el supremacismo hayan aumentado sus bases sociales en Europa ${ }^{4}$, al no sumar mayorías parlamentarias suficientes no pueden implementar políticas antinmigración. Eso no significa que el

3 Los datos han sido cuantificados de modo que si el gobierno cree que hay demasiados inmigrantes se le da el valor numérico de cero, si cree que hay pocos, dos y si cree que la cantidad es óptima, uno.

4 En las tres citas electorales al Parlamento Europeo desde 2009 los partidos nacionalistas y euroescépticos han ido aumentando el número de diputados de ochenta y seis - sobre un total de setecientos treinta y seis- a ciento dieciocho y a ciento treinta y cinco sobre un total de setecientos cincuenta y uno. Para más información, consultar: Parlamento Europeo (2019). Parlamento Europeo: 2019-2024. Sesión constitutiva. Recuperado de: https://www.europarl.europa.eu/election-results-2019/es/resultados-elecciones/2019-2024/ (22.12.2019). 
nacionalismo no esté en auge, solo que aún no ha conseguido bastante fuerza política para llevar su agenda a la practica en las instituciones.

\section{Inmigración internacional.Visión gubernamental en el mundo y por continentes, | 976-20 | |}

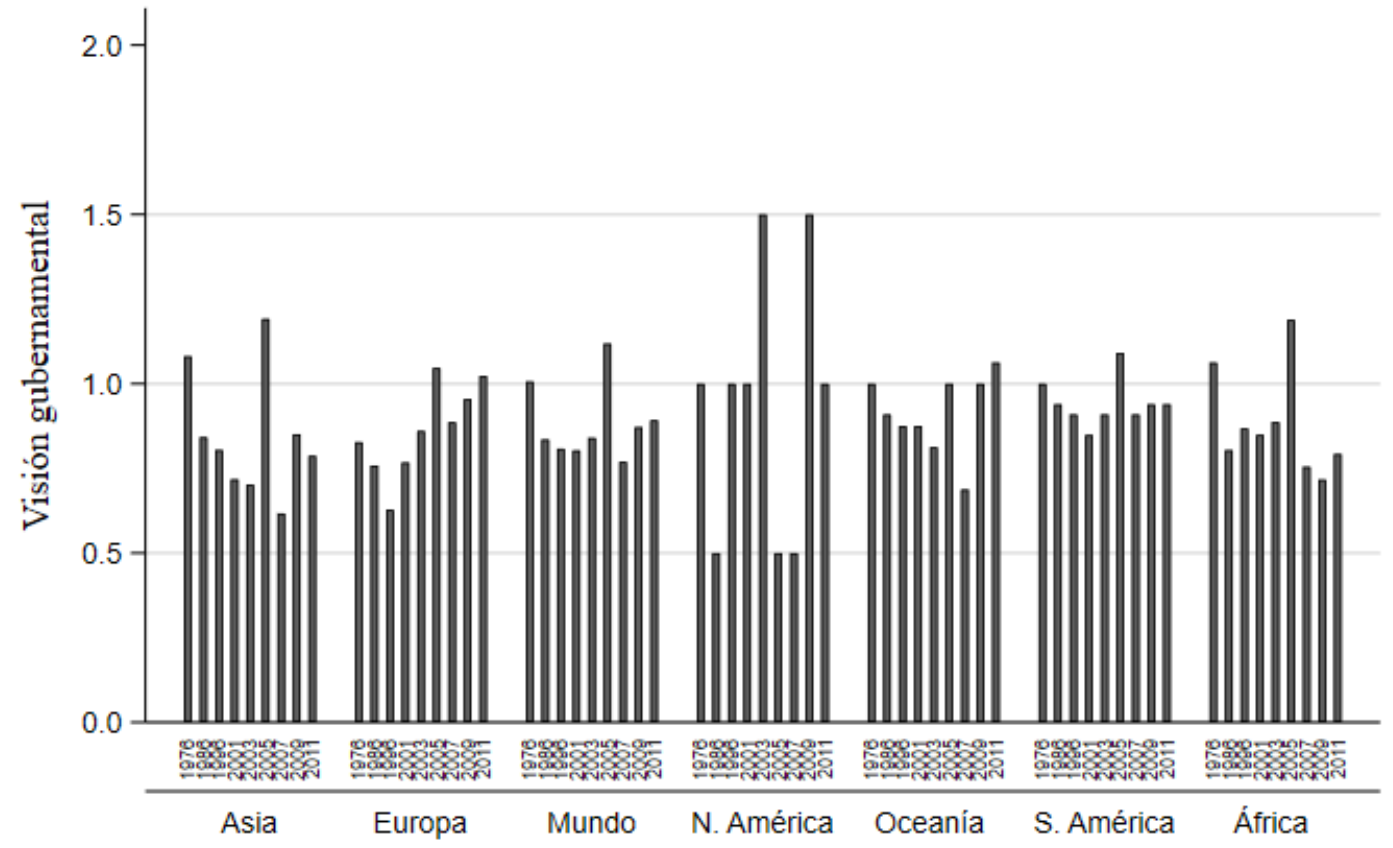

Fuente: Naciones Unidas (20/9b)

Igualmente, el auge del nacionalismo puede verse en el retraimiento de las acciones de paz de la comunidad internacional dirigidas por las Naciones Unidas —NU—. El gráfico 7, que reproducimos en la siguiente sección, muestra como el número de misiones en activo disminuye desde la década de los dos mil y, sobre todo, una importante reducción del número de misiones comenzadas.

\section{Segundo eje: apertura de fronteras. Expansión del liberalismo y "democratización" a escala global}

Durante la Guerra Fría, como hemos previamente señalado, se desarrolló un conflicto total entre la URSS y EEUU, proclamando ambas la superioridad moral de su sistema político, económico y social. Sin embargo, en muy pocas ocasiones esto escaló hasta un enfrentamiento militar. Según Stephen Martin Walt (1998, pp. 29-46), realismo y neorrealismo prevalecieron como teoría de las Relaciones Internacionales, dada la necesidad de interpretar y reconciliar los conflictos entre las dos grandes superpotencias. En cierto modo el sistema de gobernanza global alcanzó con éxito dicho objetivo. Así, si la primera mitad del siglo $X X$ vio articularse las relaciones internacionales a lo largo del cierre de fronteras, la segunda se desarrolló, mayormente, a lo largo del de apertura.

El análisis constructivista también dotará con una formulación teórica al desarrollo de las 
relaciones internacionales durante y después de la Guerra Fría (Guzini, 20 I 3, pp. 237-246). En este sentido los constructivistas examinan atentamente las ideologías, identidades y los medios que laten bajo las motivaciones de los actores políticos (Guzini, 2013, pp. 190-2I6). El constructivismo subraya que el desarrollo de comunidades culturales facilita la apertura de fronteras. De hecho, la creación de la Unión Europea (UE) es un tema popular entre los estudios constructivistas y, en general, los procesos de integración regional son otra variable que se enmarca en el eje de la apertura.

En el caso de la UE, el proceso de integración aumentó la porosidad de las culturas nacionales y disminuyó las barreras físicas entre los estados nación. Esto a la vez que desdibujó progresivamente la materialidad de las fronteras políticoterritoriales, las dotó de estabilidad e hizo disminuir las modificaciones fronterizas entre sus estados miembros (Delanty, 2006, Pp. 183-202). Algo similar ocurre en la zona oriental bajo la hegemonía cultural soviética con el $\mathrm{COMECOM}^{5}$. En general, los procesos de integración económica regional son vectores del eje de apertura, contribuyendo a estabilizar las fronteras políticoterritoriales al dejar a sus integrantes dentro de una frontera cultural común. O en palabras de Robert Schuman (1950) "la solidaridad de producción [...] pondrá de manifiesto que cualquier guerra [...] no sólo resulta impensable, sino materialmente imposible".

Podemos aplicar el mismo racionamiento al resto de $\mathrm{Ol}$ que surgen a lo largo del siglo presente y anterior. Los gráficos 2 y 3 (Pevehouse et al., 2019) muestran como la globalización durante la segunda mitad del siglo $X X$ va acompañada por la construcción de un sistema de gobernanza global que abre las fronteras mediante la puesta en común de soberanía por los estados nación. Los estados, además, crean así espacios donde las elites socializan y generan progresivamente una cultura común.

Las décadas que siguen a la Segunda Guerra Mundial son testigos de una constante creación de Ol que buscan, siguiendo los postulados realistas y neorrealistas, la creación de espacios comunes donde EEUU y la URSS dirimiesen sus conflictos. De hecho, ambas superpotencias sentaron juntas en las mismas Ol en 1.099 ocasiones a lo largo del periodo entre el final de la Segunda Guerra Mundial y la disolución de la URSS6. Sin embargo, la URSS solo tuvo membresía anual en cuatrocientas setenta y siete OI donde EEUU no estaba presente y EEUU en apenas sesenta donde su antagonista no participaba. Esto ejemplifica cómo durante la Guerra Fría, a pesar de la división del mundo en dos bloques, el eje de apertura de fronteras predominaba en la geoestrategia de las relaciones internacionales.

Será durante los años que siguieron a la Guerra Fría cuando la gobernanza global volverá a caracterizarse por un escenario similar al anterior a 1948. En este contexto se inserta la descripción por John Joseph Mearsheimer (2014) de la transformación del sistema mundo bipolar en un mundo multipolar tras el final de la hegemonía estadounidense (Keohane, 1984).Así, la caída de la URSS dotó de fuerza al eje de cierre de fronteras para después favorecer una nueva apertura.

\footnotetext{
Consejo de Ayuda Mutua Económica. Mecanismo de integración económica organizado por la URSS para la distribución de la producción y el consumo entre los países bajo su órbita.

6 En la base de datos podemos ver que en 1.099 ocasiones comparten membresía anual en las mismas OI. El
} número de veces que se encontraron en el ámbito de las actividades de esas OI nos es desconocido. 
En principio, el área sociocultural bajo la hegemonía soviética se vio fragmentada y los países bajo su órbita enarbolaron sus propias tradiciones culturales. Además, se levantaron barreras físicas, que anteriormente no existían, entre los países del bloque sin que todavía se desarticulasen las que les separaba del bloque capitalista, disminuyendo así los flujos comerciales y de personas. Esto, junto con las crisis del petróleo en los años setenta y ochenta, explica en parte la caída sostenida de los intercambios mundiales de mercancías entre 1980 y 1995, como muestra el gráfico 5. Todo esto desembocó en una verdadera modificación de fronteras con la división de Checoslovaquia, el desmembramiento de la URSS en quince repúblicas independientes, y la posterior disolución de Yugoslavia.

\section{Comercio Internacional de Mercancías. Mundo, I 960-20 I 8}

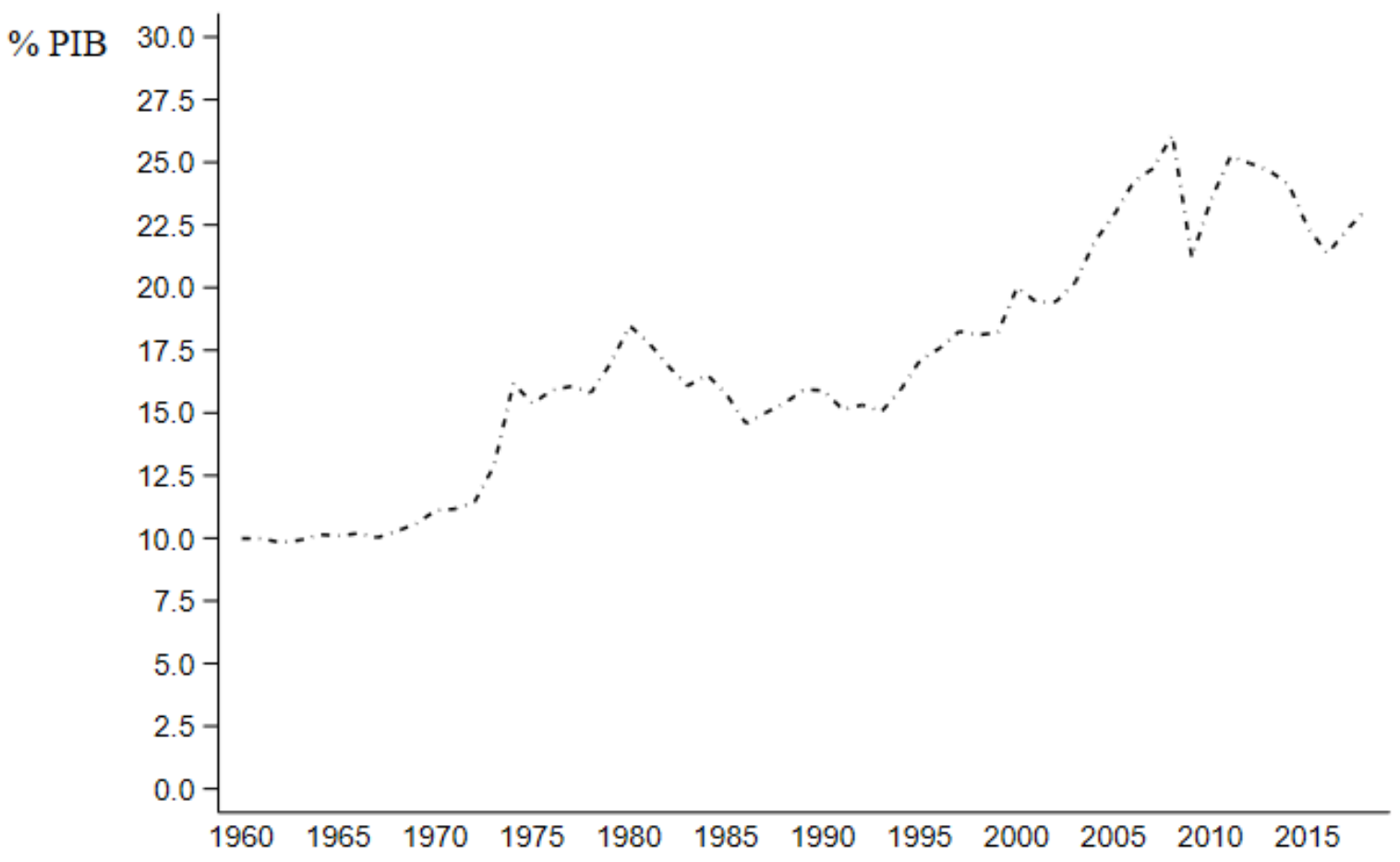

Fuente: Organización Mundial del Comercio (2019) y Banco Mundial (2019)

Sin embargo, la destrucción del sistema de hegemonía soviético favoreció a posteriori un proceso de apertura que integró a la mayoría de sus satélites en el bloque occidental. La desaparición de la URSS permitía acabar con la frontera cultural entre los países que caían bajo su área de influencia y aquellos que compartían la cultura occidental. $O$ si se prefiere, el área sociocultural propia de las poblaciones occidentales se expandía enormemente a la vez que aquella soviética se retraía. Esto también se materializó en modificaciones de las fronteras políticoterritoriales. Caso paradigmático será la reunificación de Alemania.

El triunfo del modelo de democracia parlamentaria occidental y la expansión del liberalismo económico quedaban ligados al avance de la globalización. A la vez que las fronteras se abrían y disminuían las barreras físicas al intercambio, los flujos internacionales de capital aumentaban. El 
gráfico 6 muestra como desde mediados de los ochenta, cuando comienza el desmantelamiento de la URSS ${ }^{7}$,los flujos netos de inversión extranjera directa, tanto enviados -FDIO - como recibidos -FDII—, crecen sin parar — salvo con la crisis de las dot com al inicio del milenio- hasta la crisis financiera mundial de 2007-2008. Su disminución hasta niveles cercanos a los de antes de I 985 no se explica solo por el impacto inicial de la crisis financiera sino por el posterior proceso de cierre de fronteras, vectorizado por el aumento del proteccionismo económico y el resurgir del nacionalismo. A la vez, después de 1995, según se van levantando las barreras al comercio y los países de Europa del este van estrechando relaciones con la UE, los flujos internacionales de mercancías empiezan a crecer como muestra el gráfico 5.

\section{Flujos Netos de Inversión Extranjera Directa. Mundo, I 970-20 I 8}

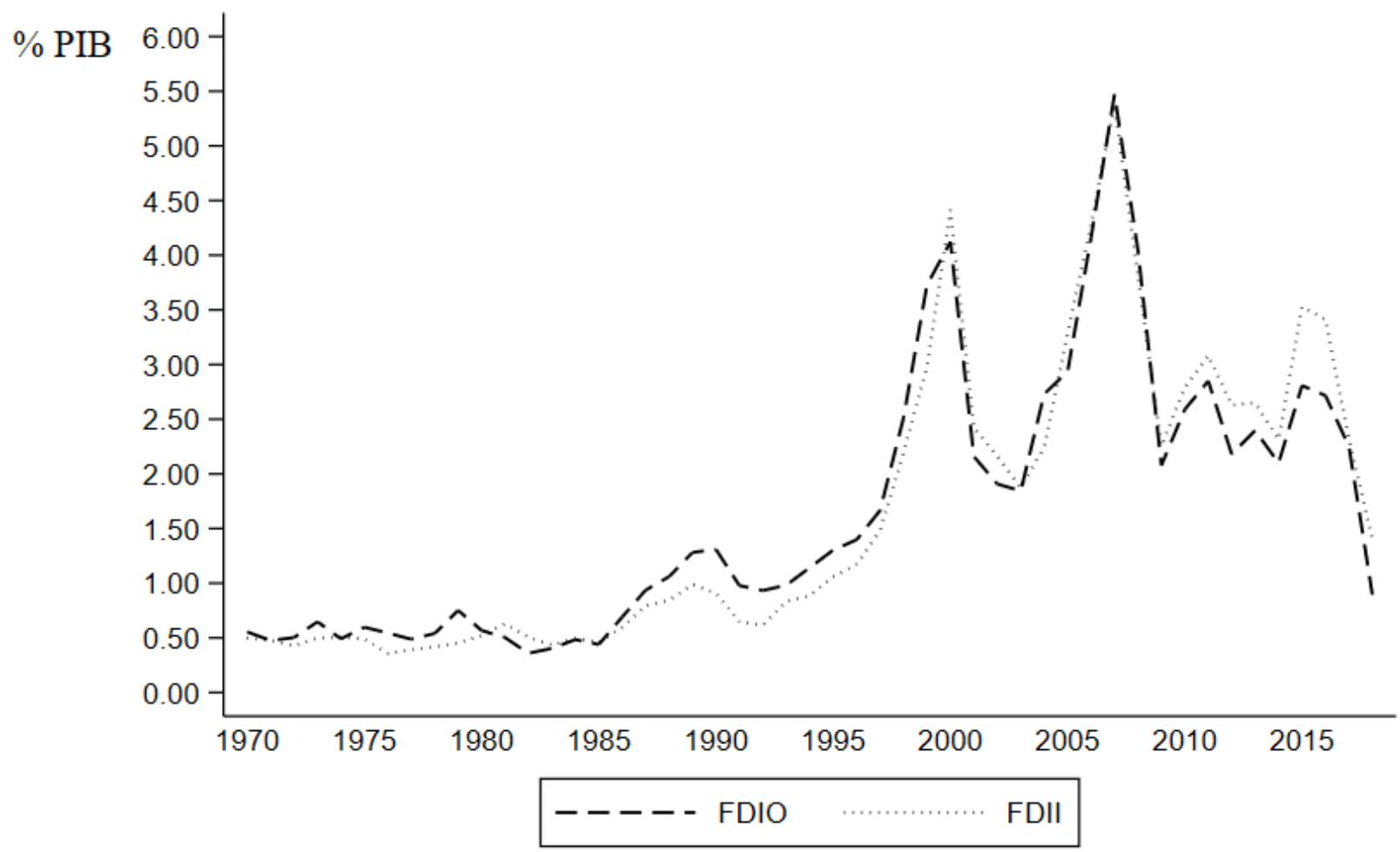

Fuente: Banco Mundial (2019)

El liberalismo político se desarrollaba paralelamente al económico. La doctrina de la autodeterminación se veía contestada y la comunidad internacional legitimada, en base a las repercusiones geopolíticas del "efecto mariposa" (Vathakou, 2007, pp. 70-98), para transgredir las fronteras políticoterritoriales en nombre de la paz y la democracia (Crespo Maclennan, 2018, pp. I-22, pp. 260-293, pp. 33 I-448). En 2005, el entonces Secretario General de las Naciones Unidas proclamó su compromiso de alertar a la ciudadanía, a las Ol y a los gobiernos nacionales de cualquier atrocidad que ocurriese en el mundo (Naciones Unidas, 2005, pp. 5-7, pp. 27-37). Pretendía así impedir su inacción cuando las violaciones de la paz y la democracia ocurriesen fuera de sus fronteras. Parecía que la operatividad de las fronteras políticoterritoriales era puesta en duda.

7 Recordemos que Gorbachev da los primeros pasos hacia la que luego seria conocida como Perestrojka en 1985. 
Una variable que confirma esta tendencia, mostrada en el gráfico 7, son las misiones de paz de las NU. No es casualidad que durante los setenta y cuatro años de funcionamiento de las NU solo quince misiones de paz, de un total de setenta y uno, empezaran antes de 1989. La capacidad de la URSS para vetar cualquier acción del Consejo de Seguridad en un contexto diplomático muy polarizado, junto con otros procesos como la descolonización, todos enmarcados en el eje del cierre de fronteras, explican su inacción hasta entonces.

Misiones de Paz de Naciones Unidas. Mundo, I948-20 I9

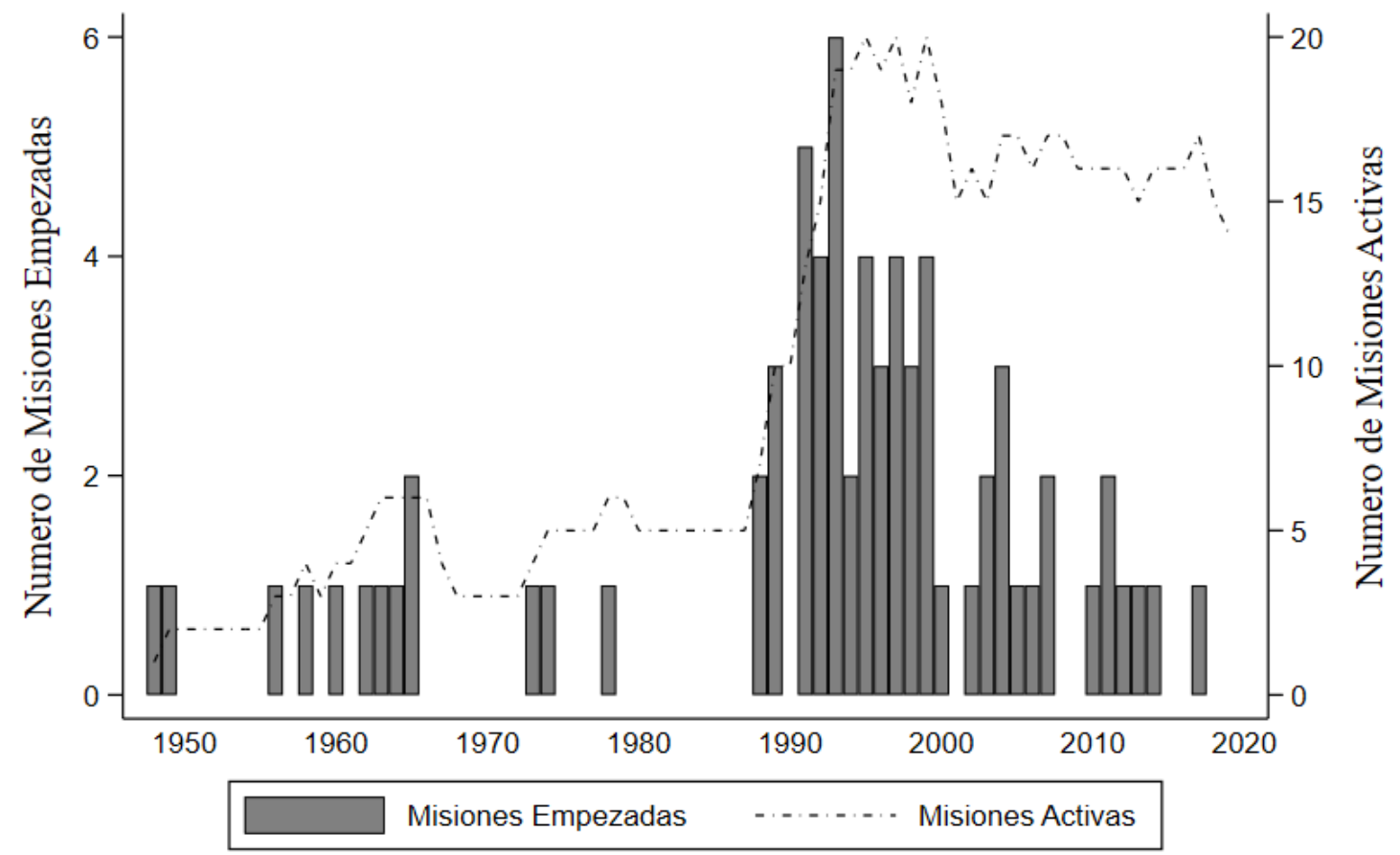

Fuente: Naciones Unidas (2019a)

El retraimiento de la gran frontera cultural que marcaba la zona de influencia socialista, a partir del final de los ochenta, posibilita la democratización masiva, de la cual las misiones de paz de las NU pueden considerarse tanto un indicador como un agente. A finales de los ochenta hay un salto cuantitativo de las misiones que empiezan cada año y también de las misiones en activo, las cuales pasan de una media de 0,3 a I,8 y de 4 a 16 respectivamente. Además, frente a lo que ocurría antes del final de los ochenta, muchas más misiones tienen lugar en lo que había sido la tradicional área de influencia soviética, comenzando con Afganistán y Pakistán en 1988, y en los países africanos, asiáticos y oceánicos que alcanzaron su independencia entre 1948 y la década de los ochenta. La historia se expandía así a lo largo del eje de apertura de fronteras.

\section{Tercer eje: modificación de fronteras. Declaraciones, anexiones y cesiones}

En esta sección analizamos los eventos enmarcados en el eje de modificación de fronteras, relacionándolos con los procesos de cierre y apertura descritos, a través de la información de las bases de datos The Correlates of War Project (Tir et al., 20I8) y The World Factbook (CIA, 20I9). En 
primer lugar, tenemos las declaraciones o reivindicaciones de independencia y auto soberanía por parte de un territorio que se erige en estado nación. Dichos eventos se asocian con los procesos inherentes al cierre de fronteras, mientras que su ausencia puede ser indicativa de un mayor protagonismo de la apertura de estas. En Cataluña vemos como las declaraciones suelen venir precedidas de un periodo de falta de coherencia entre las fronteras culturales y políticoterritoriales. En segundo lugar, tenemos las cesiones o transferencias de territorio de una entidad política a otra a través de un tratado. Pueden relacionarse principalmente con modificaciones de las fronteras culturales que se ven así ratificadas en su dimensión políticoterritorial. Finalmente, consideramos las anexiones o adquisiciones forzadas del territorio de un estado por parte de otro. Se relacionan con modificaciones de las fronteras políticoterritoriales donde el protagonista es el estado nación, sin que tenga que precederles un cambio en las fronteras culturales. En este respecto, Samuel Huntington dijo acerca del choque entre civilizaciones:

“[...] las grandes diferencias entre comunidades humanas y la fuente predominante de conflictos entre estas tendrán, en el futuro, su origen en las diferencias culturales. Los estados nación seguirán siendo los actores más poderosos en los asuntos globales, pero los principales conflictos que afectarán a la política internacional se desarrollarán entre grupos étnicos y/o grupos culturales, reviviendo el recuerdo de los califatos, las cruzadas y el colonialismo" (Huntington, 1997, p. 22).

Sin embargo, en la primera mitad del siglo $X X$ son los estados nación los principales agentes que dan lugar a los conflictos internacionales, aunque a veces la falta de coherencia entre sus fronteras políticoterritoriales y las culturales fuesen los detonantes. Tras la Segunda Guerra Mundial, que en cierto sentido fue la materialización de la crisis del estado nación debida a su degeneración hacia los nacionalismos agresivos, el elemento étnico y cultural cobra mayor predominio en la definición de las fronteras y la lucha por la supremacía adopta un cariz sociocultural (Huntington, 1997). Es por ello que las anexiones, expresión máxima de la fuerza militar del estado nación, prácticamente desaparecen como elemento geoestratégico de la gestión de fronteras tras la década de los cuarenta, como puede verse en el gráfico 8.

En este sentido, hay claras diferencias entre las dos guerras mundiales de principios del siglo XX. Así, la primera supuso el final de los últimos imperios territoriales en Europa, los cuales imponían la soberanía de un solo estado nación sobre áreas socioculturales heterogéneas. Esto explica, que la paz que la sucede y la guerra en si apenas den lugar a anexiones, sino que se articula en base a declaraciones y cesiones que buscan realinear las fronteras culturales y las políticoterritoriales, siendo casos paradigmáticos la desmembración de los Imperios austrohúngaro y turco. Por el contrario, la segunda marcará, por un lado, el último estertor de la primacía de los estados nación y sus estrategias geopolíticas basadas en la fuerza militar, lo cual explica la cantidad de anexiones que se dan en Asia y Europa durante el curso de la guerra. Por otro lado, supuso el fin de la hegemonía europea en el mundo, con la consecuente desarticulación de sus imperios extraterritoriales y una serie de cesiones y declaraciones en busca de realinear las fronteras culturales y políticoterritoriales de las antiguas colonias, sin mucho éxito en la mayoría de los casos. La Segunda Guerra Mundial también marcará el inicio de la construcción de dos nuevas macroáreas socioculturales, adscritas a las superpotencias de la Guerra Fría, explicando las 
declaraciones y cesiones que en Asia y Europa siguen al final del conflicto armado.

Modificaciones de fronteras. Mundo, 191 0-2010

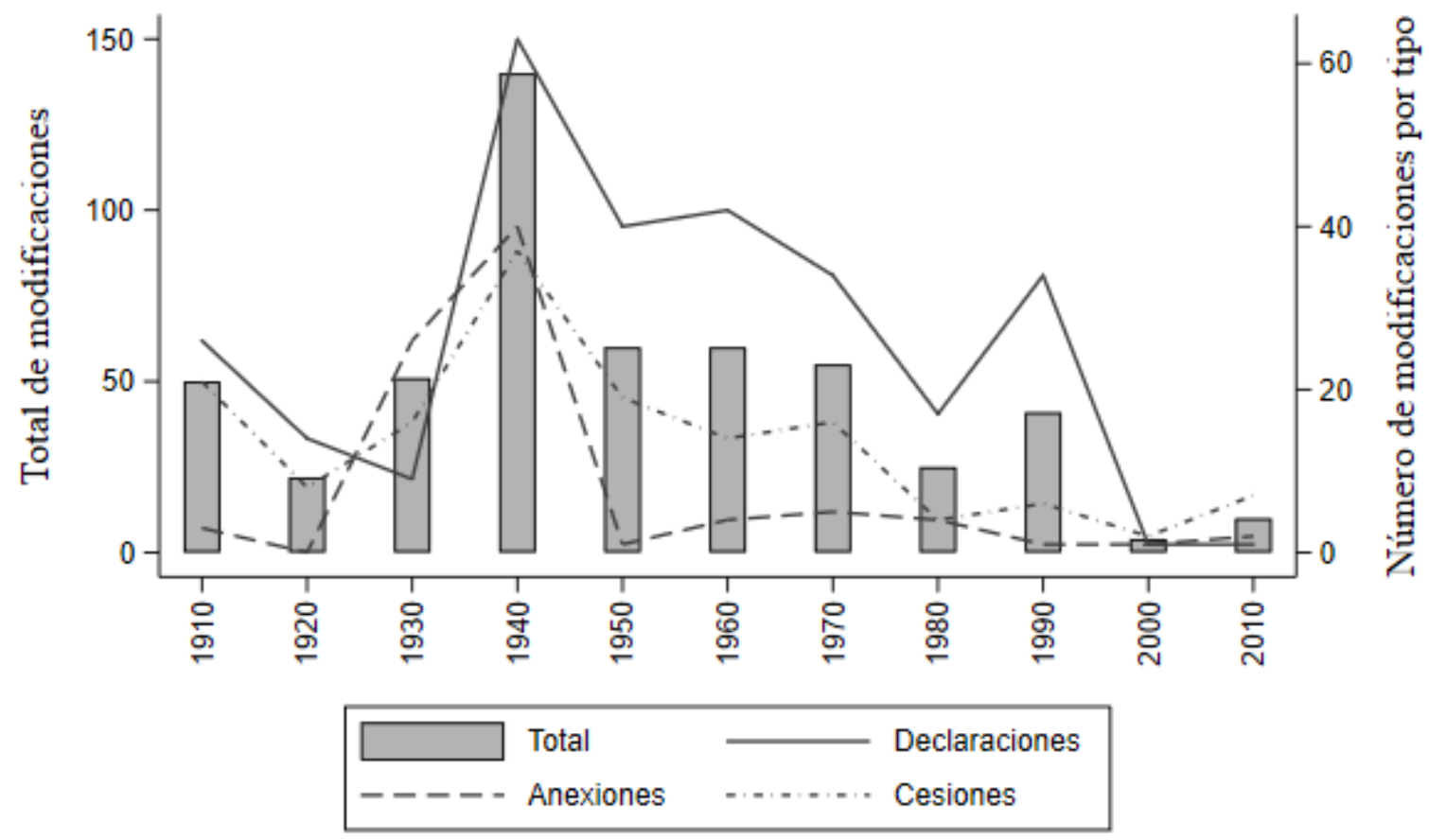

Fuente:The Correlates of War Project (Tir et al., 2018) y The World Factbook (CIA, 2019)

Otra diferencia entre las dos mitades del siglo es que Europa pasa de ser la gran protagonista en el eje de modificación de fronteras y el resto de los continentes adquieren una mayor importancia relativa, como se ve en el gráfico 9. El origen de esto también puede rastrearse en los dos grandes conflictos mundiales que, por un lado, sancionan definitivamente la decadencia de la cultura europea y, por el otro, generan las bases políticas y diplomáticas en las que se sustentarán los procesos de descolonización en Asia, África y Oceanía. 
Modificaciones de fronteras. Continentes, 19 I 0-20 10

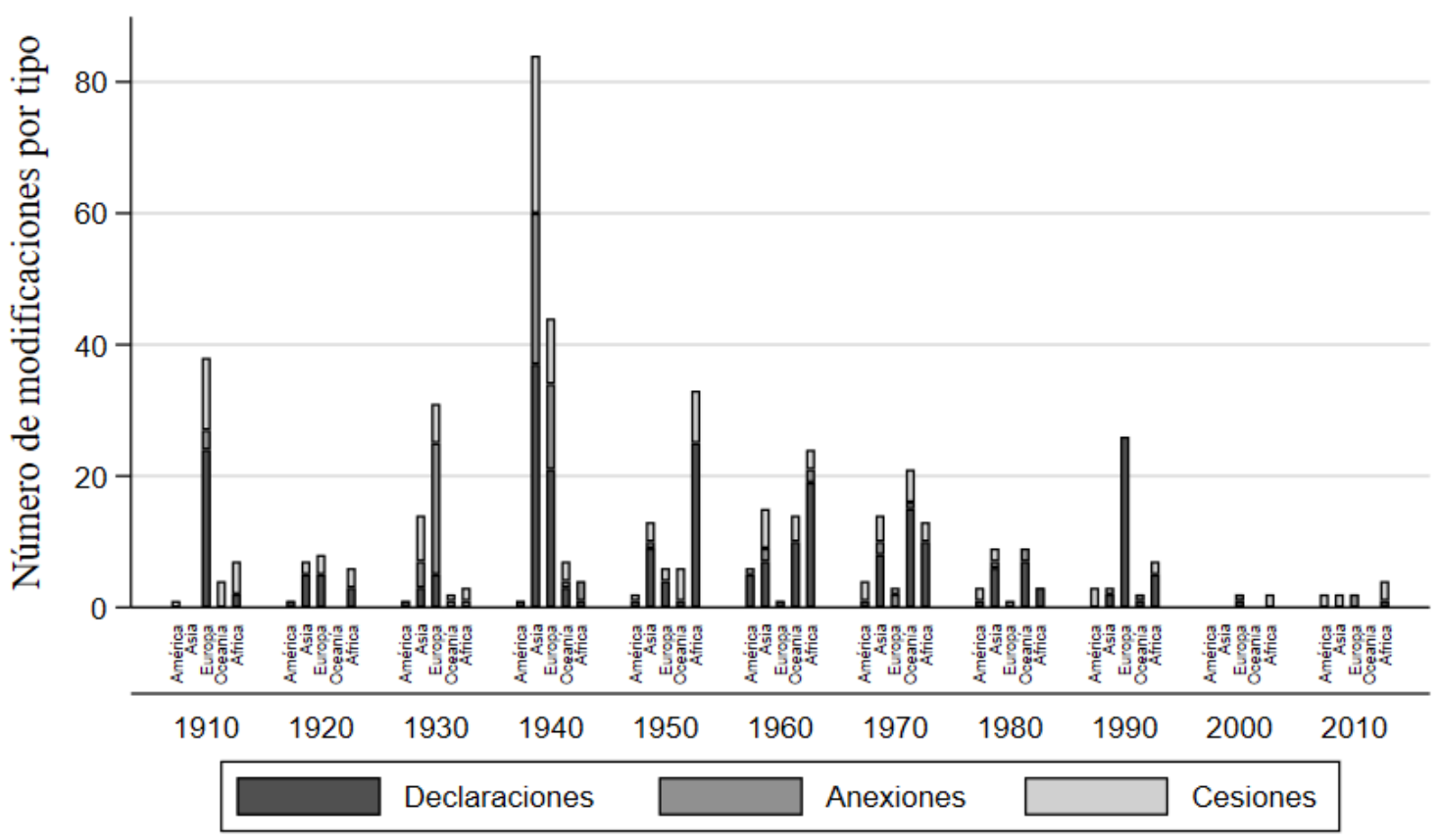

Fuente:The Correlates of War Project (Tir et al., 2018) y The World Factbook (CIA, 2019)

Finalmente, como ya venimos diciendo, en la segunda mitad del siglo $\mathrm{XX}$ el avance generalizado del eje de apertura de fronteras, aunque se diese en parte en dos bloques que actuaban como compartimentos estancos, dotará de estabilidad a las fronteras políticoterritoriales a través de la globalización y la construcción de un sistema de gobernanza global.Así, si las modificaciones fronterizas siguen una tendencia creciente hasta la década de los cuarenta, como puede verse en el gráfico 8, van disminuyendo progresivamente hasta prácticamente desaparecer en los últimos veinte años. El final de la Guerra Fría - durante la cual tanto EEUU como la URSS fomentaron las declaraciones ligadas a la descolonización-, el avance de la democracia de cuño occidental y del liberalismo económico, y la progresiva incorporación de los países de la órbita soviética a los mecanismos de integración regional y gobernanza global explican esta tranquilidad.

Hoy nos encontramos ante un tablero internacional con límites bastante estables que solo las nuevas disputas étnicoreligiosas y el terrorismo internacional están empezando a poner en cuestión. En la geopolítica moderna la lucha por la supremacía no implica a los estados nación sino a las culturas y sus proyecciones del soft power a través del choque de civilizaciones, las cuales muchas veces no precisan modificar sus fronteras políticoterritoriales para alcanzar sus objetivos. Pueden hacerlo a través de mecanismos de cooperación cultural y económica.

En el continente europeo hay un cambio estructural en las dinámicas fronterizas a partir de la década de los cincuenta. Mientras que antes de dicha fecha Europa es el continente, excepto en los cuarenta, donde las fronteras se modifican de manera más dinámica; a partir de 1950 pasa a ser el que presenta mayor estabilidad. Si dicho dinamismo se explica por el impacto de las dos Guerras Mundiales y el auge de los nacionalismos agresivos; la constitución de dos bloques estables 
durante la Guerra Fría en torno a la UE/OTAN y la URSS/Pacto de Varsovia explica la sucesiva estabilidad. Ambas estructuras supranacionales hacen innecesarias las modificaciones fronterizas ya que dentro de sus áreas de influencia los bordes de los estados nación quedaban abiertos. Siguiendo las reglas del mercado o de la planificación centralizada el fenómeno globalizador se extendió por Europa. De hecho, la tendencia contraria se constata cuando el fenómeno opuesto se materializa y la disolución del bloque comunista en los noventa llevó a un aluvión de declaraciones en Europa Central y Oriental.

Así, una vez que el proceso descolonizador se daba por terminado y el final de la Guerra Fría era evidente, todo parecía apuntar a un futuro de paz y progreso estable. Sin embargo, los desafíos para la gobernanza global no tardarían en Ilegar, empezando con la Guerra del Golfo. Es cierto que los conflictos internacionales actuales no se manifiestan en la creación de nuevos confines territoriales. En las décadas de los noventa, dos mil y dos mil diez no hay apenas declaraciones que den lugar a nuevos estados como muestra el gráfico 9. Esto señala una mayor pasividad en el eje de cierre de fronteras. Como veremos en los casos de estudio los procesos de cierre actual se caracterizan más por el establecimiento de límites al intercambio económico, cultural o social que por la creación de nuevos estados nación.

Todo esto hace surgir dudas respecto a las teorías que sitúan a los estados nación como actores principales de la política internacional. El constructivismo ha planteado nuevas hipótesis (Guzini, 20I3, pp. 237-246) donde las fuentes de conflictividad derivan del terrorismo internacional, la expansión de los populismos y de los regímenes nacionalistas autoritarios, la sucesión de crisis económicas y sociales, el auge de China y Rusia en la escena económica y política internacional, la devaluación de los valores y de la cultura occidental y el cuestionamiento de los procesos de integración regional, véase el Brexit.

A pesar de que estas tendencias aún no se han manifestado de forma masiva en una mayor modificación de fronteras, los gráficos 8 y 9 muestran un tímido repunte en las anexiones $y$, especialmente, en las cesiones durante la década actual. Destaca también que no se crean nuevas entidades políticas independientes a través de declaraciones, sino que el dinamismo se debe a dos anexiones y a siete cesiones que solo modifican algunos límites territoriales. Los casos de estudio profundizan en estas nuevas dinámicas de la gestión de fronteras.

\section{Casos de estudio: fronteras culturales contra fronteras político-territoriales en el mundo actual}

En esta sección analizamos como la tensión entre las fronteras culturales y políticoterritoriales determina la gestión de fronteras en la actualidad, siguiendo los tres ejes de apertura, cierre y modificación anteriormente delineados. Para ello, conviene recordar que los cuatro procesos que articulan la evolución de los tres ejes en la actualidad son:

- La redefinición de las relaciones internacionales posterior al final de la Guerra Fría en base a la desaparición de la gran frontera cultural entre el bloque soviético y occidental.

- La dialéctica entre el liberalismo económico y el proteccionismo de inspiración nacionalista.

- El resurgir del nacionalismo que busca redelimitar o expandir las fronteras de ciertas entidades socioculturales. 
- La importancia que tienen los elementos simbólicos y culturales y, por tanto, la necesidad de introducir herramientas tomadas del constructivismo para entenderlos.

\section{I. Cataluña y los intentos por redefinir las fronteras en el interior de la UE}

La reclamación catalana de cerrar sus fronteras parte de la valoración que las élites catalanas hacen de su integración en el Estado español y, a través de este, en la UE, tras la caída del muro de Berlín. El comunismo bolchevique ya no representa una amenaza y esto posibilita la creación de unidades políticas más pequeñas y con menor capacidad militar. El nacionalismo/regionalismo beligerante, en oposición al europeísmo/internacionalismo, vuelve a ser una alternativa viable.

El conflicto catalán ejemplifica la tensión entre el liberalismo económico y el proteccionismo de inspiración nacionalista. En cierto sentido, el nacionalismo catalán asume que las fronteras económicas tradicionales se han visto desdibujadas tras décadas de globalización —o siglos si aceptamos la tesis de Wallerstein $(2016)^{8}$ - y rediseña sus demandas de soberanía económica para hacerlas compatibles con la nueva realidad. Por ello el conflicto se plantea con respecto al estado nación -España-, el cual no es útil para los intereses de las élites catalanas. Sin embargo, no se busca la salida de la UE (EU-Catalonia Dialogue Platform, 2019) dado que les ayuda a integrarse en la economía global, reconciliando las fronteras económicas y políticas.

El auge del independentismo tiene su origen en dos hechos económicos, uno global y otro nacional. En primer lugar, la crisis financiera de 2007-2008 impide al estado mantener los equilibrios económicos entre las regiones de España como había hecho hasta entonces. Ante la escasez de recursos el independentismo ofrece una alternativa culpando a España de los problemas sociales y económicos que sufre Cataluña. La independencia se plantea como una solución a la crisis económica. En segundo lugar, mientras que el País Vasco veía aumentar su autonomía fiscal en 2007, el gobierno del Partido Popular negaría a la Generalitat de Cataluña un encaje similar en el estado de las autonomías tras rechazar el Pacto Fiscal en 2012 (Ortigosa Martín, 20 I8b). Cuando en 2014 el mismo gobierno amplió la autonomía fiscal vasca, el agravio comparativo se hizo aún mayor. El independentismo se hizo así con un argumento más para resaltar el "expolio fiscal que sufre Cataluña por parte de España" (Resolución 7I2/XI, 20I2, pp. 7-8).

Por otro lado, estudios empíricos prueban que solo en regiones culturalmente diferenciadas los conflictos económicos estimulan el secesionismo (Álvarez Pereira, Portos García y Vourdas, 2018, pp. 197-2II). Esto sucede en nuestro caso ya que Cataluña cuenta con señas culturales y trayectorias históricas propias (Real Instituto Elcano, 2017) que contribuyen a darle el carácter de nación. Desde la existencia de una lengua y una tradición literaria propia hasta sus fiestas y costumbres idiosincráticas, toda una serie de elementos culturales la diferencian de otras regiones españolas. Sin embargo, la diversidad cultural es una seña característica de la entidad política hispana.Además, la creación de una nueva frontera y un estado independiente, sin capacidad para hacer sentir sus intereses ante la comunidad internacional, no parece una solución eficiente al conflicto identitario. El reconocimiento de la plurinacionalidad de España sea en una fórmula más europeísta o federalista, junto con la redefinición de los acuerdos fiscales entre las autonomías y el estado central, previa implementación de políticas de desarrollo económico que ayuden

8 Wallerstein (2016) defiende que los límites de la economía mundo quedan formados en 1650 y que los límites de los estados nación no corresponden con estos. 
a generar el margen de maniobra fiscal necesario para la creación de mecanismos viables de solidaridad interterritorial, se plantea como una alternativa más eficiente y realizable.

En cuanto respecta a la fundamentación histórica de la frontera política entre Cataluña y el Estado español no se puede calificar el relato independentista de mera propaganda, como tampoco se puede desdeñar el grado de mitificación que lo envuelve (Ortigosa Martín, 2018a). En este sentido, la reclamación del derecho a la autodeterminación (Resolución I5I4, I960) no encuentra respaldo en la legalidad internacional, dado que Cataluña no es una colonia ni puede considerarse un pueblo oprimido.

De todas formas, es cierto que una parte de la sociedad catalana comparte la voluntad colectiva de trazar una frontera políticoterritorial con el resto de España. En ausencia de un estado que respalde esta voluntad, el constructivismo ofrece un marco teórico alternativo para analizar las causas y consecuencias del independentismo catalán. El constructivismo señala que hay variables sociológicas como el liderazgo, la cultura, la voluntad de los pueblos, etcétera que actúan como motores para la acción y el cambio político (Guzini, 2013, pp. 237-246). Estas variables están presentes en el independentismo catalán (Guzini, 2013, pp. 237-246; Baquero, 2017).Así, hay una serie de figuras que han liderado el movimiento secesionista, sea en la derecha como en la izquierda, desde artistas a políticos e incluso futbolistas (Zeleb, 20I7).

¿Cómo explica entonces el constructivismo que el procés haya fracasado hasta ahora? Simplemente, porque el signo de las variables cultura, liderazgo y voluntad popular no es claro. A pesar de disponer de claras señas culturales idiosincráticas, en Cataluña hay una fuerte influencia cultural y demográfica proveniente del resto de España. Incluso si tomamos por válido el referéndum del I-O, solo alrededor del $37,8 \%{ }^{9}$ de los catalanes se manifestó explícitamente a favor de la independencia. Tampoco faltan los líderes y referentes mediáticos que se le oponen (Zeleb, 2017). Finalmente, el orden constitucional no permite la división del territorio nacional y el Estado español si muestra una clara voluntad por mantener a Cataluña bajo su soberanía.

\subsection{Venezuela y el intento de crear un nuevo poder regional en el Caribe}

El intento venezolano de crear un nuevo foco de poder regional en Sudamérica y el Caribe muestra cierto continuismo respecto a las dinámicas geoestratégicas de la Guerra Fría. Ejemplifican el continuismo desde los discursos de Chávez, al estilo de Castro en los años cincuenta (Youtube, 2014), negando cualquier posicionamiento de corte marxista (Chávez, 2007) hasta la reciente intervención de las grandes superpotencias mundiales (El Diario, 2019), tomando partido a favor de Maduro - China y Rusia - o Guaidó —EEUU y UE-. Más aún, la presentación del conflicto con Venezuela a nivel internacional como un enfrentamiento entre ideologías totalizantes y excluyentes, el socialismo internacionalista y el —neo-liberalismo global, rememora los casus belli ${ }^{10}$ presentados por EEUU y la URSS para intervenir en terceros países. En cierto modo, se vuelve a dividir el mundo entre las dos grandes áreas socioculturales de la Guerra Fría.

Sin embargo, también hay elementos de ruptura característicos del marco de las relaciones

El $90 \%$ de los participantes en el referéndum del $1-0$ voto sí a la independencia, pero solo voto un $42 \%$ de los catalanes $(0,9 \times 0,42=0,378)$.

${ }^{10}$ Causas aceptadas por el derecho internacional para legitimar el uso de la fuerza militar contra otro estado. 
internacionales de la post Guerra Fría. Tal vez el más relevante sea la plasmación en el plano diplomático del mundo multipolar, cuyo máximo exponente es la disensión dentro de la UE a la hora de adoptar una posición ante la autodeclaración de Guaidó como presidente de la República (El Diario, 2019). Otro elemento característico en esta línea es el recurso a la guerra económica, por parte de EEUU (Gozzer, 2019), sin ningún indicio -al menos hasta muy recientemente (Gallego, 2019) - de que esto pudiese desembocar en una intervención militar directa.Asimismo, destaca el propio intento de crear un centro de poder regional independiente de las grandes superpotencias mundiales. Venezuela implementó para este fin una serie de mecanismos institucionales de cooperación económica y política en la región que no se habían visto antes, como ALBA o PetroCaribe. La misma concepción del socialismo del siglo XXI, alejado del modelo soviético o su influencia políticoeconómica, supone una ruptura respecto a las dinámicas de la Guerra Fría.

La tensión entre el liberalismo económico y el nacionalismo proteccionista también aparece en el intento de Venezuela de constituirse en potencia regional. En este caso, su orientación ideológica y económica (Sutherland, 2018), en gran parte opuesta a la realidad y los fundamentos del mundo globalizado, explica la búsqueda de equilibrio entre apertura y nacionalismo. Así, si gran parte de la industria estratégica y de la propiedad de interés social fue nacionalizada por Hugo Chávez y se han implementado controles proteccionistas sobre los precios, importaciones y exportaciones; también es cierto que tanto ALBA como PetroCaribe generaron espacios de integración/intercambio económico multilateral. Sin embargo, y aunque dichos espacios han intentado generar alternativas a la lógica capitalista liberal, Venezuela no intentó eliminar el mercado sino hacerlo más permeable a las consideraciones sociales y políticas.

PeroVenezuela no solo ha utilizado la cooperación económica para construir la base de su poder en la región. En particular, respecto a Guayana,Venezuela reclama la soberanía de Esebequio (BBC MUNDO, 2018). Esebequio es una región rica en hidrocarburos sobre la cual Venezuela reclama tener soberanía desde finales del siglo XIX. Cuando aún era colonia del Imperio británico, este llevó el caso ante los tribunales internacionales que fallaron en su favor. PeroVenezuela nunca aceptó el veredicto y, posteriormente, consiguió que el Imperio británico aceptase mantener la administración de la región, aunque reconociendo que la soberanía pertenecía a Caracas. Mientras se negociaba el estatuto final de este territorio Gran Bretaña concedió la independencia a Guayana que pasó a controlar Esebequio y las negociaciones dejaron de avanzar.

La diplomacia venezolana ha instrumentalizado el conflicto con Guayana en la construcción de su hegemonía sobre el Caribe. Si Chávez mantuvo una postura flexible respecto a Esebequio mientras utilizaba la diplomacia petrolera para aumentar su influencia en los estados del Caricom "'; Nicolás Maduro ha endurecido su postura. El descubrimiento de importantes reservas petrolíferas por Exxon Mobil en Esebequio, los problemas en el seno de PetroCaribe, la crisis económica en Venezuela y la reorientación de los países del Caricom hacia EEUU,explican este cambio de postura. Además, Guayana y Venezuela no comparten membresía en ninguna organización internacional desde 1991 (Pevehouse et al., 2019), por lo cual les falta dicho espacio de socialización y de

\footnotetext{
"Comunidad del Caribe. Es un acuerdo de integración económica y cooperación entre Antigua y Barbuda, Barbados, Belice, Dominica, Granada, Guyana, Jamaica, Montserrat, San Cristóbal y Nieves, Santa Lucía, San Vicente y las Granadinas, Trinidad y Tobago.
} 
creación de una cultura común que favorezca la apertura de fronteras entre ellas.

La teoría constructivista destaca elementos simbólicos, sociales y culturales que ayudan a explicar que Venezuela haya retomado sus reivindicaciones. Las buenas relaciones entre Chávez y el entonces presidente de Guayana, Bharrat Jadgeo, con el que además le unía la sintonía ideológica, explican por qué Chávez impulsó una política de apaciguamiento (Pardo, 20I5). Además, este apaciguamiento permitía a Venezuela ganarse a los pequeños estados caribeños con una política amistosa y una diplomacia económica cooperativa a través de PetroCaribe. El liderazgo y carisma de Chávez le permitieron dejar de lado esta tradicional reclamación fronteriza sin que los venezolanos se sintiesen agraviados.

Maduro reactivó el conflicto no solo por motivos económicos sino para reforzar su liderazgo ante el pueblo venezolano, dado su menor carisma. Por otra parte, la toma del gobierno en Guayana por un partido socialdemócrata y no marxista junto a la desaparición de las buenas relaciones interpersonales entre los líderes de ambos países, son factores que contribuyeron al resurgir de las reclamaciones territoriales. En otras palabras, cuando Guayana dejó de pertenecer a su misma área cultural Venezuela sintió la necesidad de ensanchar su frontera políticoterritorial para mantenerla bajo su influencia.

\subsection{Similitudes, diferencias y síntesis}

Para sintetizar como la gestión de fronteras opera en la actualidad analizamos las similitudes y diferencias entre los casos presentados. En primer lugar, en ambos destaca la importancia de los factores culturales y económicos. El independentismo catalán, por una parte, basa su pretensión de crear una frontera políticoterritorial en que Cataluña es una nación con unas tradiciones culturales, identidad y lengua propias. Además, considera que sufre un expolio fiscal por parte de España y que sus intereses económicos en el mundo ya están salvaguardados por la pertenencia a la UE. Por su parte, en Venezuela la rotura de la afinidad ideológica es un factor que lleva a retomar las reivindicaciones de soberanía sobre Esebequio. Sin embargo, detrás de esto hay una serie de factores económicos. En ambos casos, es también importante la actitud de los líderes.

El peso de las declaraciones de la comunidad internacional al respecto del independentismo catalán o de las demandas de soberanía de Venezuela sobre Esebequio ponen en cuestión el papel del estado nación como agente principal en la gestión de fronteras. De hecho, ninguno de los casos se plantea como una anexión, aunque también es cierto que ninguno se ha materializado en una modificación de fronteras todavía. Si el independentismo catalán aspira a una declaración de independencia ${ }^{12}$, Venezuela parece pretender conseguir que Guayana le ceda Esebequio. Sin embargo, el estado nación sí tiene un papel en la gestión de fronteras.Así, la reclamación territorial de Venezuela sobre Esebequio supone un conflicto entre dos estados nación y el Estado español tiene un papel fundamental a la hora de impedir que Cataluña se independice.

En ambos casos la falta de coherencia entre las fronteras culturales y político-territoriales está en la base de las demandas de modificación de fronteras. Una serie de dinámicas a lo largo de los ejes de apertura y cierre originan esta progresiva falta de coherencia. Sin embargo, en ninguno de los casos tiene lugar una definitiva modificación, dado que ninguno de los ejes ejerce

\footnotetext{
12 La declaracion se dio, incluso aunque fuese dejada sin efecto en el mismo momento en que se pronuncio.
} 
suficiente presión como para generar un cambio estructural. Esto también se explica por variables globales como el final de la Guerra Fría, el avance de la globalización y el sistema de gobernanza global liberal que contribuyen a dar estabilidad a las fronteras, a pesar del resurgir nacionalista y proteccionista.

\section{Conclusión:recomendaciones políticas para la transición de una "cultura de fronteras" a las "fronteras entre culturas"}

Del análisis presentado se desprende que las fronteras siguen siendo una realidad y un instrumento útil para gestionar las relaciones internacionales y facilitar la gobernanza global. Si bien en las últimas décadas la construcción de un sistema de gobernanza internacional, la globalización, el liberalismo político y la desaparición de la gran frontera cultural entre el bloque soviético y occidental han dotado de mayor estabilidad a las fronteras políticoterritoriales, todavía existen factores que las desestabilizan. Estos factores surgen de procesos como el resurgir de los nacionalismos, las crisis sociales y económicas y los intentos de proteccionismo económico. Estas variables actúan sobre los ejes de apertura y cierre de fronteras, los cuales interactúan generando modificaciones territoriales entre los estados nación.

Diferentes dinámicas históricas llevan a que las fronteras territoriales no coincidan con las culturales. Cataluña ejemplifica el choque entre la memoria colectiva y los mapas geopolíticos. Las fronteras no pueden, por definición, mantener el orden político nacional o internacional ni asegurar el equilibrio del orden mundial. Son un simple instrumento y su utilidad queda determinada por el uso que le dan sus gestores. Mantenerlas inalterables puede causar tanta inestabilidad como adaptarlas.

El estudio de la gestión de fronteras tiene que fundamentarse sobre un enfoque sintético e interactivo. El realismo explica eficientemente las dinámicas fronterizas anteriores a la Guerra Fría, dado el carácter protagonista de los estados nación. Sin embargo, con la descolonización y, sobre todo, tras el final de la Guerra Fría los elementos sociales y cultural pasan a ser centrales en la evolución de la gestión de fronteras. No se pueden explicar estas dinámicas sin recurrir al constructivismo, a pesar de que los estados nación mantengan cierta importancia y no puedan desecharse todas las aportaciones del realismo y otros marcos teóricos.

En conclusión, los estados nación ya no pueden seguir utilizando las estrategias que utilizaban hace más de medio siglo para alcanzar sus objetivos geoestratégicos. Ni la diplomacia tradicional ni las alianzas militares y el uso de la fuerza les permitirán ya alcanzar sus objetivos geopolíticos. La cooperación económica y cultural, la construcción de redes de influencia a través de la difusión de paradigmas culturales, la creación de sistemas de valores sociales y políticos compartidos y la socialización de las élites y los dirigentes políticos en espacios de gobernanza global se plantean como herramientas más eficientes y efectivas a la hora de hacer valer las aspiraciones de un estado nación ante la comunidad internacional. 


\section{Referencias}

Álvarez Pereira, B., Portos García, M. y Vourdas, J. (20I8). Waving goodbye?: the determinants of autonomism and secessionism in Western Europe. Regional Studies, 2 (52), I97-2 I I. DOI: I0.1080/00343404.2017.1282609

Banco Mundial (2019). Data Bank, World Development Indicators. Recuperado de: https://databank.worldbank.org/ source/world-development-indicators (20.12.2019).

Baquero, C.(2.10.2017). Un 90\% de 'síes'con 2,2 millones de votos y una participación del 42\%, según el Govern. Recuperado de: https://elpais.com/ccaa/20I7//0/02/catalunya/I506898063 586836.html (2.04.2020).

BBC MUNDO (30.03.2018). El Esequibo, el territorio que disputan Venezuela y Guyana desde hace más de 50 años. Recuperado de: https://www.bbc.com/mundo/noticias-america-latina-43600074 (2.04.2020).

Chávez, H. (28.08.2007). Hugo Chávez reniega del marxismo-leninismo. Recuperado de: https://www.youtube.com/ watch?v=2bll4Uii5GI (I6.09.20I9).

CIA (2019). The World Fact Book. Recuperado de: https://www.cia.gov/library/publications/the-world-factbook/ (7.07.2019).

Crespo Maclennan, J. (2018). Europa: how Europe shaped the modern world. Nueva York: Pegasus Books.

Delanty, G. (2006). Borders in a changing Europe: dynamics of opennes and closure. Comparative European Politics, 2-3 (4), I83-202. DOI: I0.1057/palgrave.cep.6I I0073

El Diario (24.01.2019). Los países que reconocen al autoproclamado Juan Guaidó y los que apoyan a Nicolás Maduro. Recuperado de: https://www.eldiario.es/internacional/paises-apoyan-autoproclamacion-JuanGuaido 0 860564l70.html (2.04.2020).

EU-Catalonia Dialogue Platform (2019). EU-Catalonia Dialogue Platform. Recuperado de: https://www.eucatplatform. $\mathrm{eu} /(2.09 .2019)$.

Fukuyama, F. (1992). The End of History and the Last Man. Nueva York: Free Press.

Gallego, M. (I3.04.2019). EEUU eleva la amenaza military sobre Venezuela. Recuperado de: https://www.hoy.es/ internacional/eeuu/eleva-amenaza-militar-venezuela-20 I 904 I 3223307-ntrc.html?ref=https:\%2F\%2Fwww. google.com\%2F (2.04.2020).

Gozzer, S. (7.03.2019). Crisis en Venezuela: qué está haciendo el gobierno de Nicolás Maduro para sortear las sanciones económicas de EEUU. Recuperado de: https://www.bbc.com/mundo/noticias-america-latina-4744II72 $(2.042020)$

Grimson, A. (julio, 2019). Fronteras, naciones y región. Trabajo presentado en el Fórum Social das Américas, Quito.

Guzini, S. (20I3). Power, realism and constructivism. Abingdon: Routledge.

Hopkins, A. G. (20I7). Globalisation and decolonisation. The Journal of Imperial and Commonwealth History, 5 (45), 729 745. DOI: 10.1080/03086534.2017.1370218

Huntington, S. (1997). The Clash of Civilizations and the Remaking of World Order. Londres: Penguin Books.

Keohane, R. (1984). After Hegemony: Cooperation and Discord in the World Political Economy. Nueva Jersey: Princeton University Press.

Kristof, L. K. D. (1959). The Nature of Frontiers and Boundaries. Annals of the Association of American Geographers, 3 (49), 269-282. DOI: I0.IIII/j. I467-8306.1959.tb0 I6I3.x

Mearsheimer, J. (20I4). The tragedy of Great Power politics. Nueva York:W.W. Norton \& Company.

Medina Garcia, E. (2019). Fronteras políticas y paisajes culturales en los límites del estado nación. Revista de historiografia, 30, 73-95. DOI: 10.203 I8/revhisto.2019.4744

Naciones Unidas (2005). Un concepto más amplio de la libertad: desarrollo, seguridad y derechos humanos para todos. Recuperado de: https://www.un.org/spanish/largerfreedom/report-largerfreedom.pdf (I I.09.20I9).

Naciones Unidas (2015). World Population Policies Database. Recuperado de: http://esa.un.org/poppolicy/about_ database.aspx. (24.12.2019).

Naciones Unidas (2019a). List of past peacekeeping operations. Recuperado de : https://peacekeeping.un.org/sites/ default/files/unpeacekeeping-operationlist_3_0.pdf (2I.I2.2019).

Naciones Unidas (2019b). Population Division. World Population Policies 1976-20I5. Recuperado de: https://esa.un.org/ PopPolicy/about_database.aspx (24.12.2019).

Organización Mundial del Comercio (2019). Data. Recuperado de: https://data.wto.org/ (20.12.2019).

Ortigosa Martín, J. L. (2018a). La cuestión catalana I: desde la Prehistoria hasta la "Guerra de Sucesión”. Madrid:Visión Libros.

Ortigosa Martín, J. L. (20 I8b). La cuestión catalana II: desde junio de I 7 / 3 hasta junio de 20 I8. Madrid:Visión Libros.

Pardo, D. (21.07.20I5). Por qué Venezuela reclama dos tercios del territorio de Guyana. Recuperado de: https://www.bbc. com/mundo/noticias/2015/07//50720_venezuela_guyana_claves_diferendo_dp (2.04.2020).

Pevehouse,J. C.W., Nodstron, T., McManus, R.W., Spencer Jamison,A. (2019).Tracking Organizations in the World:The Correlates of War IGO Version 3.0 datasets. Journal of Peace Research. DOI: I0.1 I77/00223433 I988। I75

RAE (2020). Real Academia Española. Recuperado de: https://dle.rae.es/etno- (2.04.2020).

Real Instituto Elcano (2017). El conflicto catalán. Recuperado de: http://www.realinstitutoelcano.org/wps/ wcm/connect/8ca9ef80-5dcd-435I-8I7d-3efc49|4I2c2/Cataluna-Dossier-Elcano-Octubre-20I 7. pdf?MOD=AJPERES\&CACHEID=8ca9ef80-5dcd-435I-8I 7d-3efc49|4I 2c2 (20.10.20I9).

Resolución I5I4 (XV), de I4 de diciembre de 1960, Declaración sobre la concesión de la independencia a los países y pueblos coloniales. Asamblea General de las Naciones Unidas, 947 sesion plenaria, de 14 de diciembre de 1960. Recuperado de: https://www.un.org/es/decolonization/declaration.shtml (25.06.20l8). 
Resolución 7/2/XI, de 27 de septiembre de 2012, Orientación política general del Gobierno de la Generalidad. Parlamento de Cataluña, Tram. 255-00006/09, de 27 de septiembre de 2012. Recuperado de: https://www. parlament.cat/document/intrade/6053 (20.10.2019).

Rumford,C.(2006).Theorizing Borders. European Journal of SocialTheory, 9 (2), I 55- I69.DOI: I 0. I I 77// 36843 I 006063330

Schuman, R. (9.05.1950). Declaración de Robert Schuman. Recuperado de: https://europa.eu/european-union/abouteu/symbols/europe-day/schuman-declaration_es (22.11.2019).

Sendhart, B. (2013). Border Types and Bordering Processes: A Theoretical Approach to the EU/Polish-Ukrainian Border as a Multi-Dimensional Phenomenon. En Lechevalier,A.yWielgohs, J. (Eds.). Borders and Border Regions in Europe: Changes, Challenges and Chances (pp. 2 I-44). Bielefeld:Transcript Verlag.

Sutherland, M. (20I8). La ruina de Venezuela no se debe al "socialismo" ni a la "revolución". Nueva Sociedad, 274. Recuperado de: https://nuso.org/articulo/la-ruina-de-venezuela-no-se-debe-al-socialismo-ni-la-revolucion/ (25.10.2019).

Tir,J.,Schafer,P.,Diehl,P.y Goertz,G.(20 I 8).Territorial Changes, I 8I 6-20 I 8:Procedures and Data. ConflictManagement and Peace Science. Recuperado de: http://www.correlatesofwar.org/data-sets/territorial-change (25.06.2019).

Vathakou, E. (2007). The autopoiesis of conflict transformation: An example of a 'butterfly effect' in Greek-Turkish relations. En Stetter, S. (Ed.). Territorial conflicts in world society: modern systems theory, international relations and conflict studies (pp. 70-98). Nueva York: Routledge.

Wallerstein, I. (2016). El moderno sistema mundial l: la agricultura capitalista y los orígenes de la economía-mundo europea en el siglo XVI. Madrid: Siglo XXI.

Walt, S. M. (1 998). International Relations: One World, Many Theories. Foreign Policy, I I0, 29-46. DOI: I0.2307/I I49275

Youtube (22.09.20 14). Amazing: Fidel Castro says they are no communist or Marxist. Recuperado de: https://www.youtube. com/watch?v=jqn ljHGv_L8 (16.09.2019).

Zeleb. (6.09.2017). 22 famosos catalanes a favor y en contra de la independencia. Zeleb. Recuperado de: http://www. zeleb.es/n/22-famosos-que-tienen-algo-que-decir-sobre-la-independencia-de-cataluna-020629 (25.10.2019). 


\section{RELACIONES INTERNACIONALES}

Revista académica cuatrimestral de publicación electrónica Grupo de Estudios de Relaciones Internacionales (GERI)

Universidad Autónoma de Madrid, España

https://revistas.uam.es/relacionesinternacionales

ISSN 1699 - 3950

f facebook.com/RelacionesInternacionales

3. twitter.com/RRInternacional

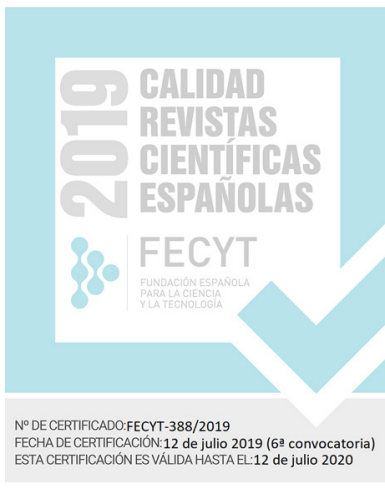

